\title{
Synthesis of well-ordered MCM-41 containing highly-dispersed NiO nanoparticles and efficient catalytic epoxidation of styrene
}

\author{
KAI HUANG*, ZHILI WANG and DONGFANG WU \\ School of Chemistry and Chemical Engineering, Southeast University, Jiangning District, Nanjing 211189, \\ China \\ E-mail: huangk@seu.edu.cn
}

MS received 5 January 2018; revised 11 April 2018; accepted 11 April 2018; published online 1 June 2018

\begin{abstract}
Well-ordered MCM-41 materials with different loadings of $\mathrm{NiO}$ were prepared combining hydrothermal method using cetyltrimethylammonia bromide as the structure-directing agent in an ammonia aqueous solution with calcination. A series of characterization of the resulting samples revealed that the materials maintained ordered mesostructure of MCM-41 after loading $\mathrm{NiO}$ and $\mathrm{NiO}$ nanoparticles were highly dispersed in the mesoporous wall and on the external surface of MCM-41. Characterization results also unveiled that $\mathrm{Ni}^{2+}$ prefer to enter the pores that formed by silicone gel during the hydrothermal reaction and incorporated into the pore wall and then formed $\mathrm{NiO}$ during the calcination process. And the TEM images indicated that smaller size $\mathrm{NiO}$ nanoparticles are easier to be formed on the MCM-41 materials. Catalytic results revealed that $\mathrm{NiO}$ should be the catalytic active centers for the oxidation of styrene and Ni-based materials showed the efficient catalytic property.
\end{abstract}

Keywords. NiO/MCM-41; heterogeneous catalysis; styrene; epoxidation.

\section{Introduction}

Nowadays, transition metal oxide catalyst such as nickel oxide, ${ }^{1}$ cobalt oxide, ${ }^{2}$ copper oxide, ${ }^{3}$ manganese oxide, ${ }^{4}$ vanadium oxide, ${ }^{5}$ molybdenum oxide, ${ }^{6}$ bimetallic oxide ${ }^{7}$ and polymetallic oxide ${ }^{8}$ are widely synthesized and used. Among these oxides, nickel oxide is a binary transition metal oxide with a wide range of applications as a p-type semiconductor with a wide band gap. ${ }^{9}$ In particular, due to the effect of quantum confinement, the nickel oxide with nanostructure shows excellent optical, magnetic and electronic properties. Owing to its high theoretical specific capacitance, nickel oxide is also a promising material as an electrode of supercapacitor. ${ }^{10}$ Furthermore, nickel oxide can also be applied to catalyze the oxidation of $\mathrm{CO}$, methanol and hydrazine, ${ }^{11}$ epoxidation of styrene and cyclooctene, ${ }^{12}$ decomposition of ethanol, ${ }^{13}$ dehydrogenations of ethane, ${ }^{14}$ etc.

However, since the nanoparticle would easily be aggregated into large bulk, quantum-confined nickel oxide nanoparticles, especially the highly-dispersed nickel oxide nanoparticles, tend to be difficult to obtain during synthesis. ${ }^{15}$ Therefore, in the process of catalyst synthesis, a support is necessary to disperse the nanoparticles to prevent agglomeration. Mesoporous silica is well-known for its high specific surface area, high porosity and oriented channels, which are the characteristics of ideal catalyst support materials. ${ }^{16}$ Particularly, mesoporous MCM-41 is a promising support because of its large surface area, high thermal stability and large pore size. ${ }^{17}$

Numerous studies have revealed that $\mathrm{NiO}$ as an active phase showed a superior catalytic performance in olefin epoxidation. ${ }^{18}$ Additionally, nickel complexes as active phase, supported over ordered mesoporous silica as catalysts for olefin epoxidation, have also been reported. ${ }^{19}$ Styrene oxide is an important intermediate for a large variety of fine chemicals. ${ }^{20}$ So catalytic oxidation of styrene to styrene oxide is significant from both academic and commercial point of view. $\mathrm{NiO}$ supported on $\mathrm{Al}_{2} \mathrm{O}_{3}{ }^{21}$ has been used as a catalyst for epoxidation of styrene. However, due to the fact that the specific surface area of $\mathrm{Al}_{2} \mathrm{O}_{3}$ is not high enough $\left(336.7 \mathrm{~m}^{2} / \mathrm{g}\right), \mathrm{NiO}$ was not highly dispersed, resulting in the conversion of styrene to only $60.2 \%$. Therefore, using materials with higher specific surface area as support could improve the catalytic activity of the catalyst.

\footnotetext{
*For correspondence
} 

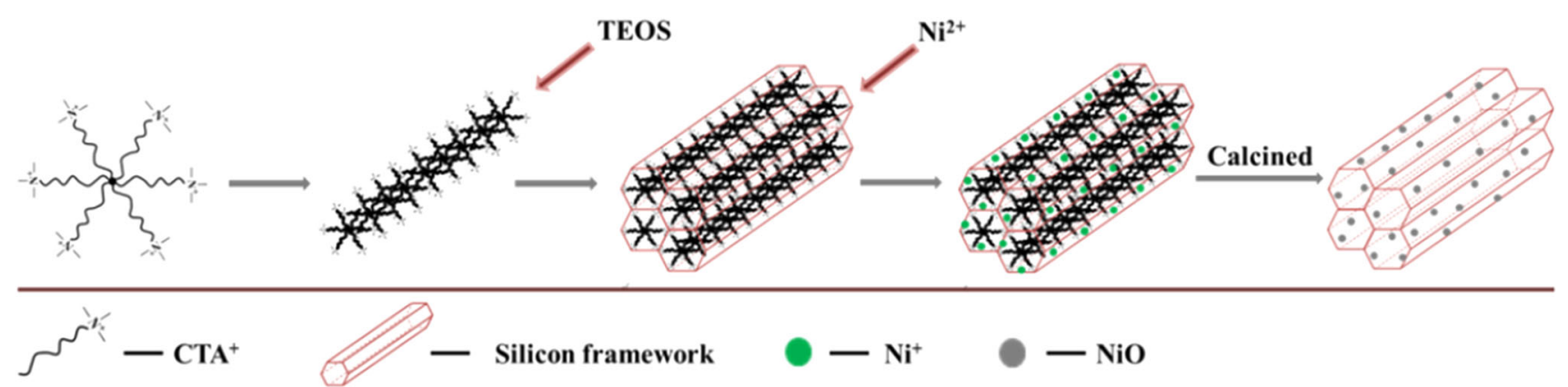

Scheme 1. The schematic illustration for the synthetic route of xNi-MCM-41.

Considering this, we chose MCM-41 with the high specific surface area as support and synthesized supported catalysts with different nickel oxide loadings via the method of combining hydrothermal with calcination. The catalysts were used to catalyze epoxidation of styrene, and to the best of our knowledge, using nickel modified MCM-41 as a catalyst for the selective epoxidation of styrene has not been reported.

Herein, we proposed a novel templating self-assembly route based on the electrostatic assembly mechanism, and the route could illustrate the formation mechanism of the hexagonal channel in MCM-41 adequately. Scheme 1 illustrates the process, formation of micelles by surfactants dispersed in water, and subsequently rod-like micelles due to the aggregation of micelles. Afterwards, the addition of silicon source resulted in the self-assembly of micelles and the formation of the hexagonal outline. Then, electronegative silicate oligomers would match with electropositive ions in the tail of the micelles and an inorganic silicon wall formed on the surface of the organic hexagonal prism, eventually. After that, $\mathrm{Ni}[2+]$ anchored on the surface of silicon gel entered the pores that are formed by silicone gel under the effect of surfactant during the hydrothermal reaction and formed highly-dispersed $\mathrm{NiO}$ nanoparticles on the surface and pore wall of MCM-41 material during the calcination process.

\section{Experimental}

\subsection{Materials and synthetic procedures}

Tetraethyl orthosilicate (TEOS, AR), cetyltrimethyl ammonium bromide (CTAB, AR), ammonia (25\%, AR), nickel nitrate hexahydrate $\left(\mathrm{Ni}\left(\mathrm{NO}_{3}\right)_{2} \cdot 6 \mathrm{H}_{2} \mathrm{O}, \mathrm{AR}\right)$, acetonitrile $\left(\mathrm{CH}_{3} \mathrm{CN}, \mathrm{AR}\right)$ and tert-butyl hydroperoxide (TBHP, AR) were purchased from Sinopharm Chemical Reagent Co., Ltd. Styrene $\left(\mathrm{C}_{8} \mathrm{H}_{8}, \mathrm{AR}\right)$ was purchased from Shanghai Macklin Biochemical Co., Ltd.
A typical synthetic process for the preparation of modified MCM-41 follows the reported procedures ${ }^{22}$ with minor modification. In a typical synthesis, $2.62 \mathrm{~g}$ of CTAB was dissolved in $125 \mathrm{~mL}$ of deionized water, and then $36 \mathrm{~mL}$ of $25 \%$ ammonia was added to the solution under vigorous stirring. Then, $14 \mathrm{~mL}$ of TEOS was slowly added to the above solution. After $0.5 \mathrm{~h}$ of stirring at $35^{\circ} \mathrm{C}$ and the hydrolysis of TEOS was complete, the resulting solution turned milk-white, then different amounts of $\mathrm{Ni}\left(\mathrm{NO}_{3}\right)_{2} \cdot 6 \mathrm{H}_{2} \mathrm{O}(2,4,6 \mathrm{mmol})$ as nickel source were dissolved in deionized water and were added to the above solutions, respectively. After that, the resulting gel was allowed to crystallize at $110^{\circ} \mathrm{C}$ for $52 \mathrm{~h}$ in a Teflon-lined autoclave. The sample was filtered, washed with deionized water up to neutral $\mathrm{pH}$, and dried at $60^{\circ} \mathrm{C}$ for $12 \mathrm{~h}$. Finally, the resultant powder was calcined at $550^{\circ} \mathrm{C}$ for $6 \mathrm{~h}$. The samples corresponding to different nickel amount were labelled as $\mathrm{xNi}-\mathrm{MCM}-41$, in which $\mathrm{x}$ stands for the amount of nickel in different samples.

For comparison, pure MCM-41 was synthesized via the above procedure without the addition of nickel source. Pure $\mathrm{NiO}$ nanoparticles were also synthesized by following the procedures of preparing Ni-base MCM-41 without adding TEOS.

\subsection{Characterization methods}

Crystalline phases of the catalysts were measured by $\mathrm{X}$ ray Diffraction (XRD) with a $\mathrm{Cu} K \alpha$ radiation source $(\lambda=$ $0.15406 \mathrm{~nm}$, Smartlab, Rigaku). The X-ray tubes worked at $40 \mathrm{kV}$ and $30 \mathrm{~mA}$. The small angle XRD was recorded over the $2 \theta$ range of $1--10^{\circ}$ with a step size of $0.02^{\circ}$ at an acquisition time of $0.4 \mathrm{~s}$. The wide-angle XRD was collected over the $2 \theta$ range from $10^{\circ}$ to $80^{\circ}$ with a step size of $0.1^{\circ}$ at a collection time of $0.3 \mathrm{~s}$. Crystal phases were identified by Joint Committee on Powder Diffraction Standards (JCPDS) files.

Textural properties of the samples were derived from $\mathrm{N}_{2}$ adsorption/desorption measurement at $77 \mathrm{~K}$ on Quadrasorb SI 2MP. Prior to the measurement, the samples were outgassed at $150^{\circ} \mathrm{C}$ for $12 \mathrm{~h}$. The average pore diameter and pore size distribution curves were established from the adsorption branches of isotherms using the Barrett-Joyner-Halenda (BJH) method.

Surface morphology of the catalysts was examined by transmission electron microscopy (TEM) (Tecnai-G20, FEI) 
and operated at an accelerating voltage of $200 \mathrm{kV}$. The samples were dispersed ultrasonically in ethanol and then deposited on a TEM copper grid before the measurement.

The loadings of nickel in catalysts were measured using Inductively Coupling Plasma spectrometer (ICP) (Spectroblue ICP-OES). Fourier transform infrared (FT-IR) spectra were recorded in the range of 400-4000 $\mathrm{cm}[-1]$ on Thermo Fisher Nicolet 5700 spectrophotometer in $\mathrm{KBr}$ pellets. UVVis diffuse reflectance Spectrometer (DRS) (UV-2600, Shimadzu) equipped with a diffuse reflectance accessory was used. The spectra were recorded in the range $200-800 \mathrm{~nm}$ at room temperature.

Surface chemical composition of the samples was investigated by X-ray photoelectron spectroscopy (XPS) (K-Alpha, Thermo Fisher) equipped with a standard $\mathrm{Al} \mathrm{K} \alpha$ excitation source (1486.6 eV). The C1s peak at $284.6 \mathrm{eV}$ was used as the reference for binding energies.

The reduction behavior of the prepared materials was investigated by hydrogen temperature-programmed reduction (TPR) measurement on a chemisorption analyzer (Micor 2920, Micromeritics) equipped with a thermal conductivity detector (TCD). TPR is a convenient technique for studying the reduction behavior of supported oxide materials reducible at different temperature intervals. Before the TPR analysis, the carbonate and hydrate' impurities were removed by flowing argon over the catalyst at a flow rate of $30 \mathrm{~mL} / \mathrm{min}$ at $300{ }^{\circ} \mathrm{C}$ for $1 \mathrm{~h}$ and the system was then cooled to room temperature. The amount of $\mathrm{H}_{2}$ uptake during the reduction was measured continuously using TCD.

\subsection{Catalytic activity measurements}

The epoxidation of styrene reaction was carried out in a 50 $\mathrm{mL}$ two-necked flask equipped with a condenser. Generally, $1041.5 \mathrm{mg}$ styrene, $7.9 \mathrm{mg}$ acetonitrile and $50 \mathrm{mg}$ catalyst were added to a $50 \mathrm{~mL}$ two-necked flask, then $10 \mathrm{mmol}$ tert-butyl hydroperoxide as oxidant was added. Finally, the reaction began after immersing the flask into oil bath, and kept at $80{ }^{\circ} \mathrm{C}$. The reaction was carried out under magnetic stirring. The products of epoxidation were analyzed by a gas chromatograph (INESA GC-126) equipped with OV-1701 capillary column and a FID detector with toluene as internal standard. The characterization of the main and by-products were performed by comparison of their retention times with standard samples. The alkene conversion and selectivity of products were calculated from peak area by standard addition method using Eqs. (1) and (2), respectively:

$$
\begin{aligned}
& \text { Conversion }(\%)=\frac{\text { mole of reactant converted }}{\text { mole of the reactant in feed }} \times 100 \\
& \begin{aligned}
\text { Product selectivity }(\%) \\
=\frac{\text { mole of the product formed }}{\text { mole of the reactant converted }} \times 100
\end{aligned}
\end{aligned}
$$

In a typical experiment, after recovering the catalyst from the reaction mixture at optimum conditions, it was washed several times with acetonitrile and dried, and then reused under the same conditions for catalyst reusability test.

\section{Results and Discussion}

\subsection{Structure and morphology}

The X-ray powder diffraction measurement was used to characterize the crystallographic structure of the synthesized materials. The small-angle XRD patterns of samples are shown in Figure 1A. An intense main diffraction peak and two small peaks were well-resolved at $2.1^{\circ}, 3.6^{\circ}$ and $4.2^{\circ}$, corresponding to the (111), (200) and (220) planes, which are the characteristics of the
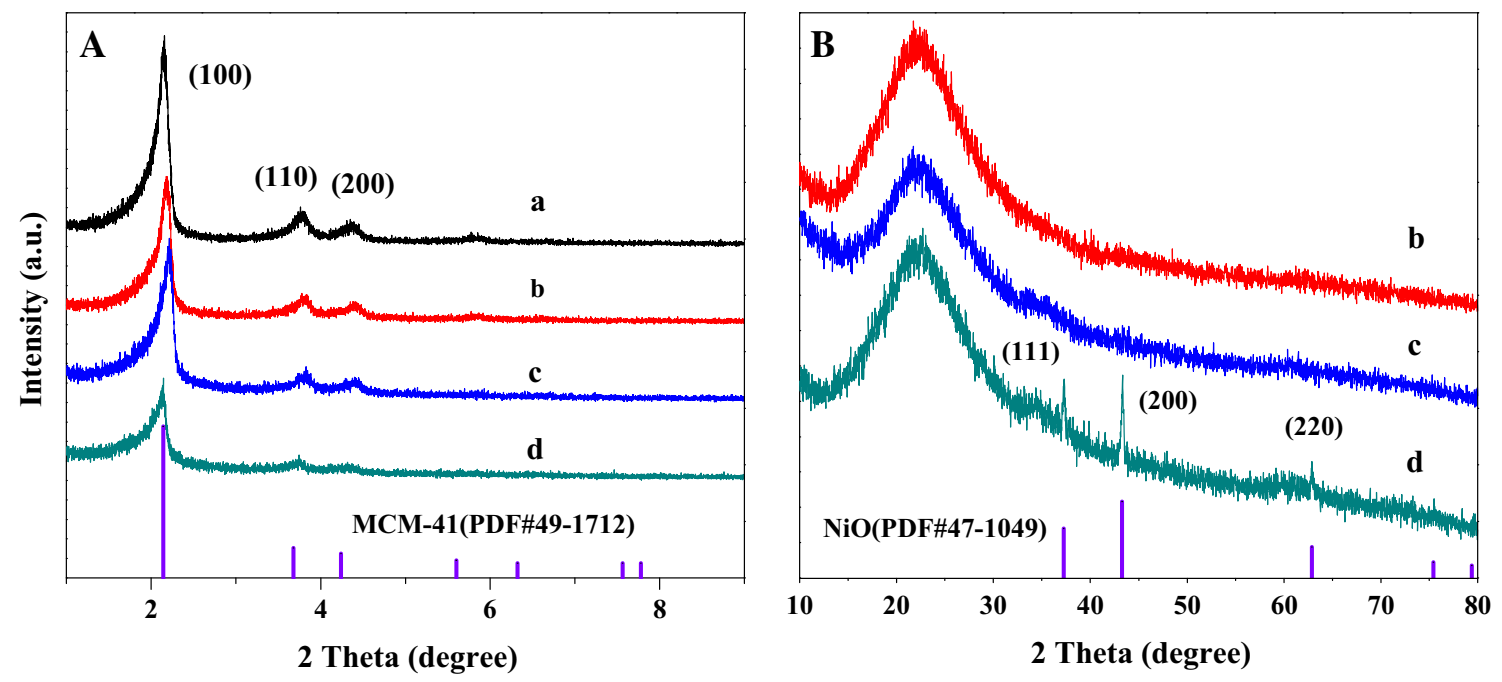

Figure 1. Small-angle (A) and large-angle (B) XRD patterns of samples: (a) MCM-41, (b) 2Ni-MCM-41, (c) 4Ni-MCM-41, (d) 6Ni-MCM-41. 
Table 1. The textural properties of samples.

\begin{tabular}{lcccccccc}
\hline Materials & $\begin{array}{c}\mathrm{Ni} / \mathrm{Si}{ }^{\mathrm{a}} \\
\text { Initial mixture }\end{array}$ & Product & $\begin{array}{c}\mathrm{d}_{100} \\
(\mathrm{~nm})\end{array}$ & $\begin{array}{c}\mathrm{a}_{0}^{\mathrm{b}} \\
(\mathrm{nm})\end{array}$ & $\begin{array}{c}\mathrm{S}_{B E T} \\
\left(\mathrm{~m}^{2} / \mathrm{g}\right)\end{array}$ & $\begin{array}{c}\text { Pore volume }^{\mathrm{c}} \\
\left(\mathrm{cm}^{3} / \mathrm{g}\right)\end{array}$ & $\begin{array}{c}\text { Pore size } \\
(\mathrm{nm})\end{array}$ & $\begin{array}{c}\mathrm{W}_{d}^{\mathrm{e}} \\
(\mathrm{nm})\end{array}$ \\
\hline MCM-41 & & $-\overline{0}$ & 3.92 & 4.53 & 795 & 0.86 & 2.80 & 1.73 \\
2Ni-MCM-41 & 0.03 & 0.018 & 3.92 & 4.53 & 829 & 0.97 & 2.79 & 1.74 \\
4Ni-MCM-41 & 0.06 & 0.045 & 3.84 & 4.43 & 767 & 1.10 & 2.78 & 1.65 \\
6Ni-MCM-41 & 0.09 & 0.085 & 3.81 & 4.40 & 722 & 1.28 & 2.63 & 1.77 \\
\hline
\end{tabular}

${ }^{\text {a}}$ From ICP (molar ratio).

${ }^{\mathrm{b}}$ Hexag onal unit cell parameter.

${ }^{\mathrm{c}, \mathrm{d}}$ Calculated from adsorption branch with BJH method.

${ }^{\mathrm{e}} \mathrm{W}_{d}=\mathrm{a}_{0}$ - Pore size.
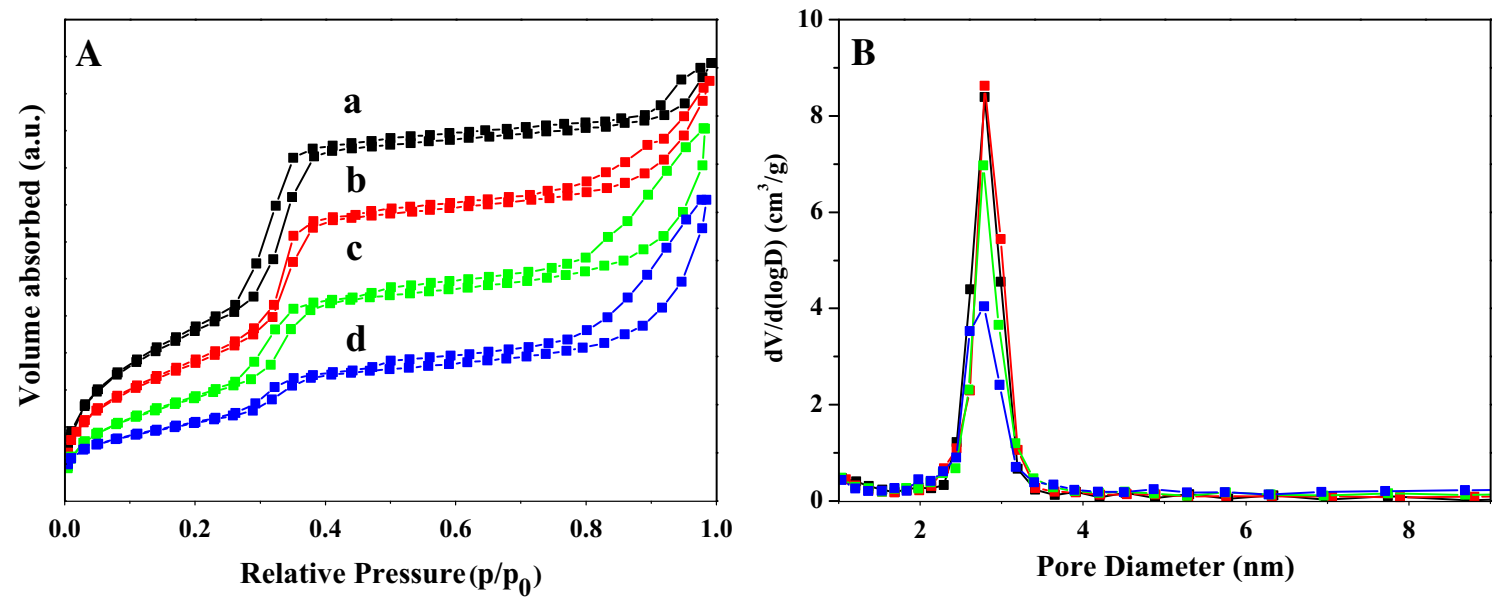

Figure 2. $\mathrm{N}_{2}$ adsorption-desorption isotherms (A), and pore size distribution curve derived from the adsorption branch (V: pore volume, D: pore diameter) (B) for samples with different nickel oxide loadings: (a) MCM-41, (b) 2Ni-MCM-41, (c) 4Ni-MCM-41 and (d) 6Ni-MCM-41.

hexagonal pore mesostructure of the synthesized materials (JCPDS 49-1712). ${ }^{23}$ Compared with pure MCM-41, the diffraction peak of Ni-based materials was shifted toward higher angles, indicating the decrease of $d_{100}$ interplanar spacing, which can be seen in the data in Table 1. The $d_{100}$ values were obtained from Jade 5.0 and the hexagonal unit cell parameter $\mathrm{a}_{0}$ was calculated byh the equation, $a_{0}=2 d_{100} \sqrt{ } 3$. The increase of the $d-$ values and $\mathrm{a}_{0}$ can be attributed to the higher ionic radii of $\mathrm{Ni}^{2+}(69 \mathrm{pm})$ in comparison to $\mathrm{Si}^{4+}(40 \mathrm{pm})$ and due to the longer bond lengths of $\mathrm{Ni}-\mathrm{O}$ in comparison to $\mathrm{Si}$ $\mathrm{O}$ bonds,${ }^{24}$ suggesting the successful incorporation of $\mathrm{NiO}$.

Furthermore, when the load of nickel was less than or equal to $4 \mathrm{mmol}$, there was no obvious change in the intensity of the peaks, indicating that the structural integrity was retained after modification. However, when the load of nickel reached $6 \mathrm{mmol}$, the intensity of the peaks weakened, especially for the intensity of (100) peak, indicating that the structures were retained but with a slight distortion of the channels. ${ }^{25}$
In large-angle XRD patterns (Figure 1B), all samples showed a broad diffraction peak at $23^{\circ}$, which was ascribed to the amorphous framework of MCM-41. ${ }^{26}$ And, 6Ni-MCM-41 revealed three peaks corresponding to (111), (200) and (220) reflections assigned to the crystalline NiO (JCPDS 47-1049). While for 4Ni-MCM-41, several weak peaks which are specific to nickel oxide were detected. As for $2 \mathrm{Ni}-\mathrm{MCM}-41$, the peak that corresponds to nickel oxide was hardly found, suggesting that no $\mathrm{NiO}$ nanoparticle was present on the external surface of MCM-41 materials or the micro-morphology grain formed was below the detection limit of XRD. ${ }^{27}$ These results indicated that the emerging crystal diffraction peaks were accompanied by an enhanced trend with the increase of nickel loading in the samples, owing to the increment of crystallinity and enlargement of grain size for nickel oxide nanoparticles according to Scherrer's Equation. ${ }^{28}$

To further investigate the textural information of all samples, the $\mathrm{N}_{2}$ adsorption/desorption isotherms and pore size distributions were obtained and depicted in 

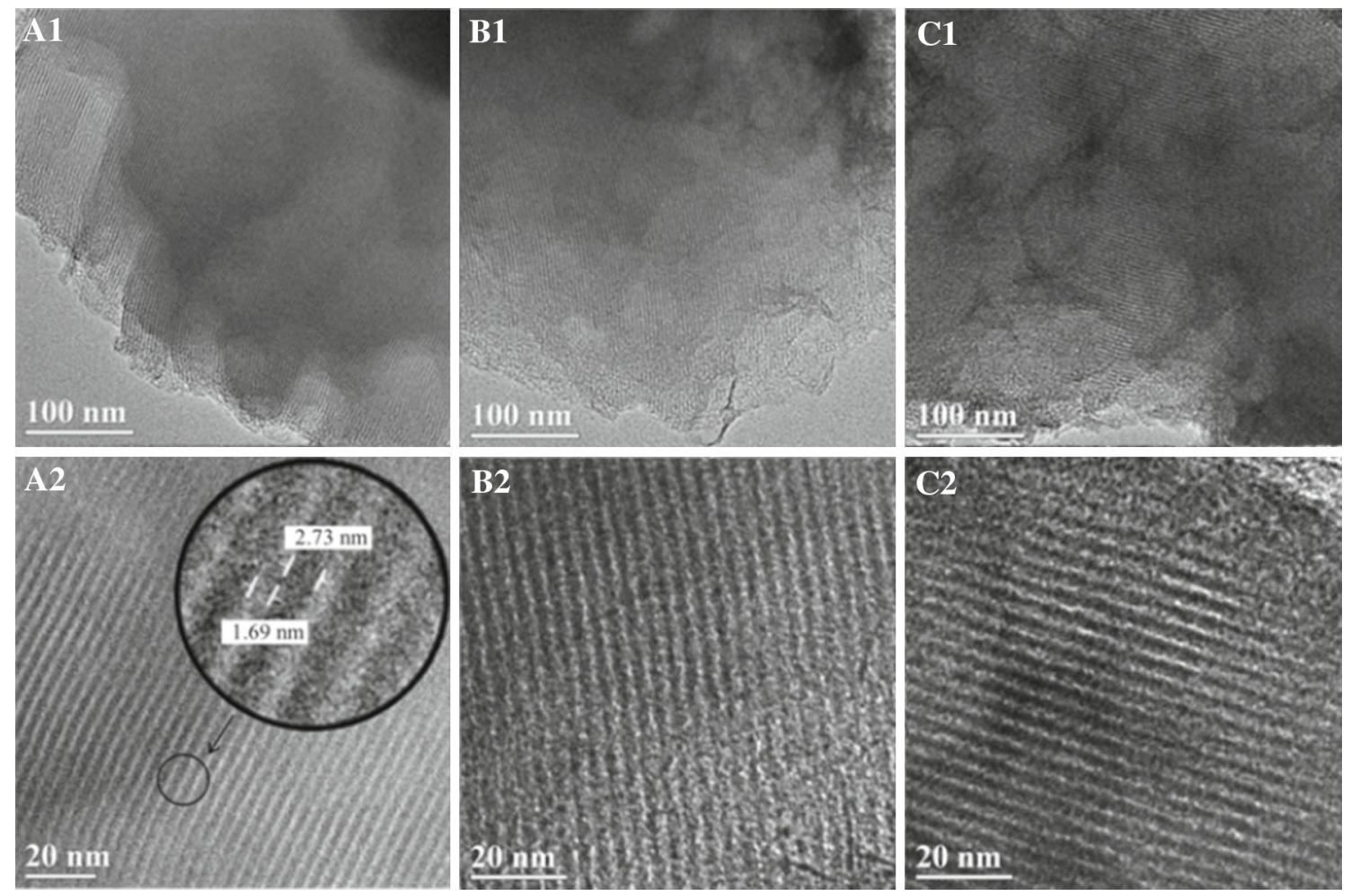

Figure 3. TEM images of MCM-41 ( $a_{1}$ and $\left.a_{2}\right), 2 N i-M C M-41\left(b_{1}\right.$ and $\left.b_{2}\right)$ and $4 \mathrm{Ni}-\mathrm{MCM}-41\left(\mathrm{c}_{1}\right.$ and $\left.\mathrm{c}_{2}\right)$.

Figure $2 \mathrm{~A}$ and $\mathrm{B}$, respectively. The surface areas were measured with the BET method, pore sizes were calculated from the adsorption branch by BJH method. The surface area, pore volume, pore size and wall thickness $\left(\mathrm{W}_{d}\right)$ are also summarized in Table 1 . As observed in Figure 2A, all the samples exhibited typical IUPAC type IV adsorption isotherm with a $\mathrm{H}_{1}$ type hysteresis loop, indicating that the mesostructure of the synthesized samples ${ }^{29}$ and the incorporation of nickel oxide did not obviously destroy the mesophase of the samples. And along with the increase of nickel loading in the samples, the size of the hysteresis loop varied with an increasing trend, indicating a declining trend of pore size of samples (Table 1).

For all the samples, another common feature is that the sharp step over the narrow range of relative pressure at $\mathrm{P} / \mathrm{P}_{0}$ of $0.25-0.4$ corresponded to the characteristic of capillary condensation inside the conventional mesoporous present in MCM-41 structure. ${ }^{30}$ Upon nickel incorporation, the location of the inflection step remained the same, suggesting that all the samples kept ordered mesoporous structure (Figure 2B), while the sharpness turned flat and the adsorption amount decreased significantly, owing to the fact that the declining specific surface area (Table 1) restrained monolayer adsorption of nitrogen towards the walls of the mesopores. ${ }^{31}$ Furthermore, as shown in Figure 2B, all the prepared materials were mesoporous with a narrow pore size distribution at the range of $2.5-3.5 \mathrm{~nm}$. And the vertices of the curves all appeared at $2.75 \mathrm{~nm}$, indicating that the number of pores with a diameter of $2.75 \mathrm{~nm}$ is the most.

The TEM images of the samples are shown in Figures 3 and 4. For MCM-41, the well-ordered mesopores and straight channel are clearly depicted. The diameter of mesopores was about $2.73 \mathrm{~nm}$ and the thickness of mesoporous wall was about $1.69 \mathrm{~nm}$ (inset Figure $3 \mathrm{a}_{2}$ ), so the distance between two cylindrical mesopores was about $4.42 \mathrm{~nm}$. The data is consistent with the data in Table 1. Compared to the pure MCM-41, Nibased materials also showed well-ordered mesoporous channel with minor defects in mesoporous walls as a consequence of incorporation of nickel oxide nanoparticles in the walls. Moreover, $\mathrm{NiO}$ nanoparticles were not observed over 2Ni-MCM-41 and 4Ni-MCM-41, but the data from Table 1 confirms the presence of nickel and the molar ratio of nickel to silicon is very close to that of the initial mixture. $\mathrm{NiO}$ nanoparticles could be observed over 6Ni-MCM-41 (Figure 4B), and the results are consistent with XRD analysis.

The selected-area electron diffraction (SAED) pattern and the particle-size distribution of $\mathrm{NiO}$ nanoparticles are also shown in Figure 4. Diffraction rings assigned to the (111), (200), (220) and (311) planes of $\mathrm{NiO}$ 

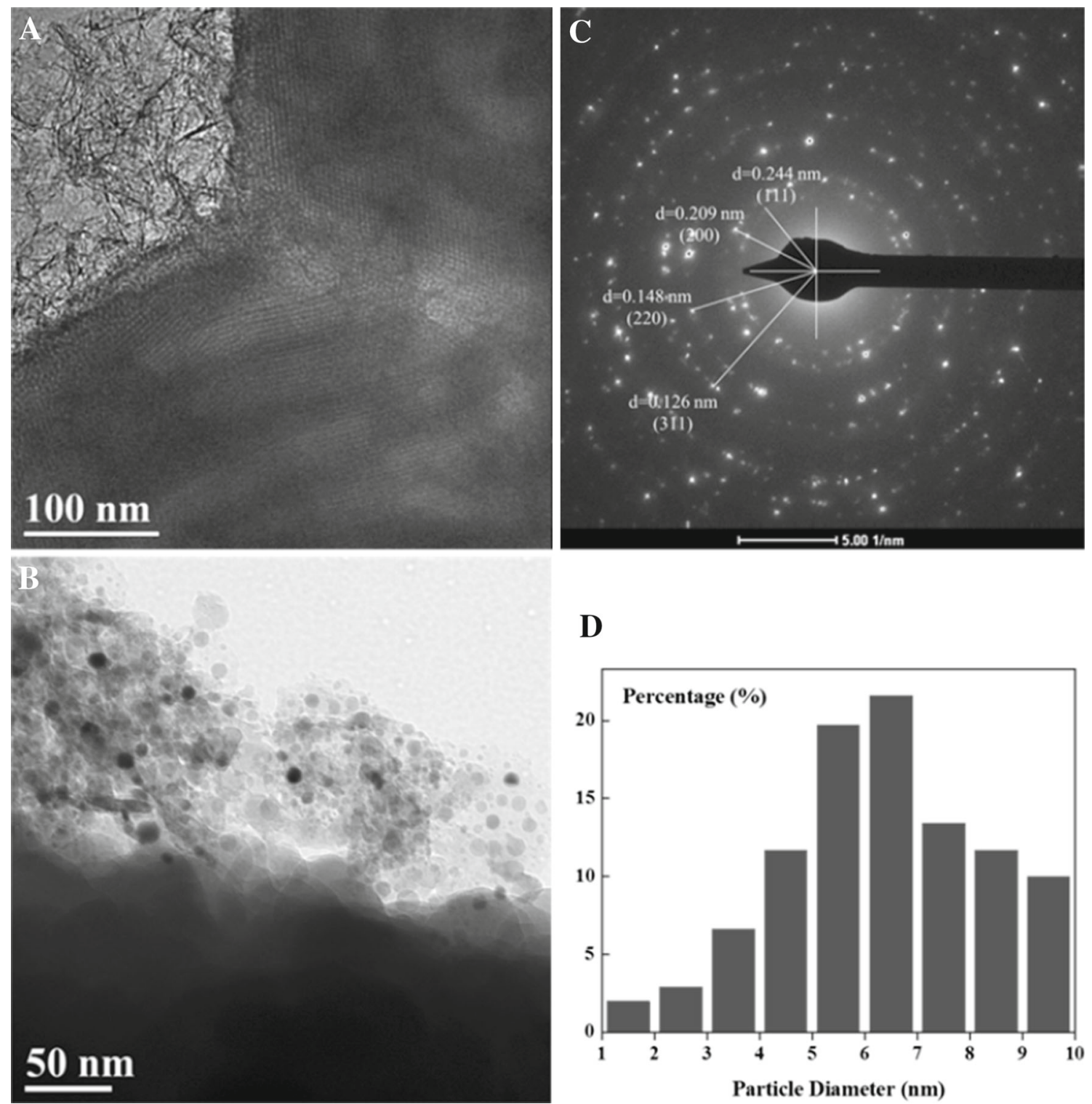

\section{D}

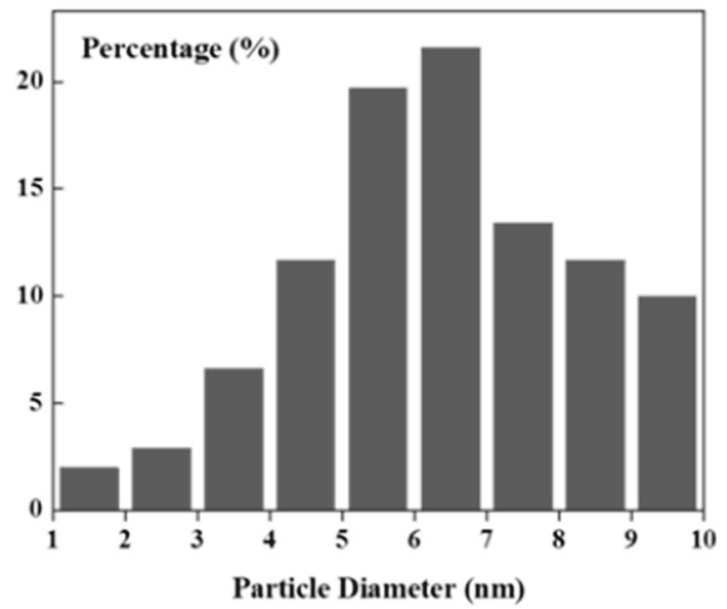

Figure 4. TEM images of 6Ni-MCM-41 (A and B) and SAED pattern (C), particle-size distribution of $\mathrm{NiO}$ nanoparticles (D).

nanocrystals are clearly seen in Figure 4C. As shown in Figure 4D, the particle size of the $\mathrm{NiO}$ nanoparticles varied from 1 to $10 \mathrm{~nm}$, and the vast majority was in the 5-7 nm range.

The TEM image and XRD pattern of as-prepared pure $\mathrm{NiO}$ nanoparticles are presented in Figure 5. The sharp diffraction peaks (Figure 5B) are assigned to $\mathrm{NiO}$ nanocrystals (JCPDS 47-1049) which proved that the $\mathrm{NiO}$ with high crystallinity had been synthesized successfully. As shown in Figure 5A, the length and width of rod-like $\mathrm{NiO}$ nanoparticles are about $42 \mathrm{~nm}$ and $24 \mathrm{~nm}$, respectively. While the maximum size of $\mathrm{NiO}$ nanoparticles supported on MCM-41 is only about $10 \mathrm{~nm}$, which is much smaller than that of pure $\mathrm{NiO}$ nanoparticles, indicating that the silicon source is beneficial to the formation of small size $\mathrm{NiO}$ nanoparticles.

\subsection{State of nickel species}

Figure 6 shows the FT-IR spectra of all samples in the region from 4000 to $400 \mathrm{~cm}^{-1}$. The band at $3445 \mathrm{~cm}^{-1}$ observed in all samples are ascribed to the symmetrical stretching vibration of - $\mathrm{OH}$ groups on the surface of MCM-41 and the band at $1627 \mathrm{~cm}^{-1}$ is assigned to the bending vibration of adsorbed water. ${ }^{32}$ The bands at 1083 and $808 \mathrm{~cm}^{-1}$ are related to the asymmetric stretching vibration and symmetric stretching vibration of 

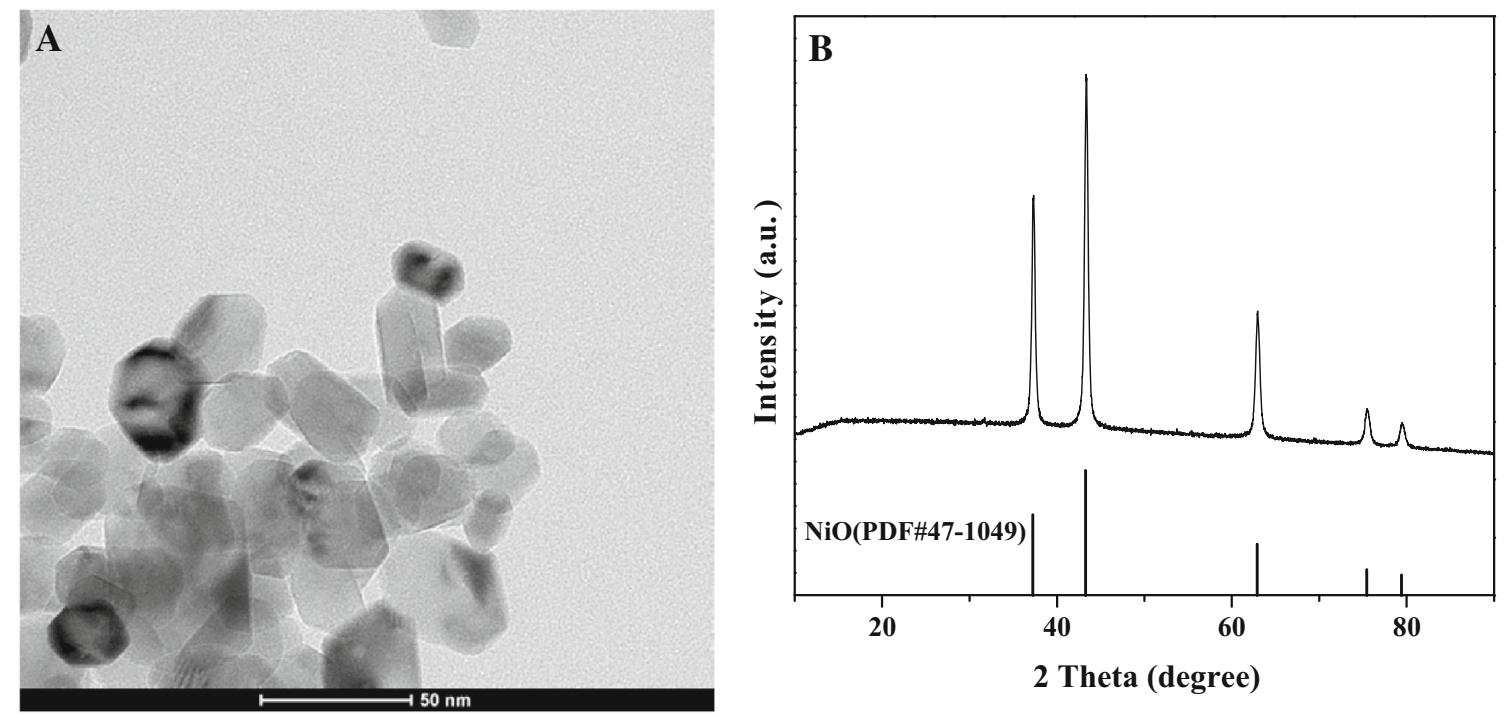

Figure 5. (A) TEM image and (B) XRD pattern of prepared $\mathrm{NiO}$ nanoparticles.

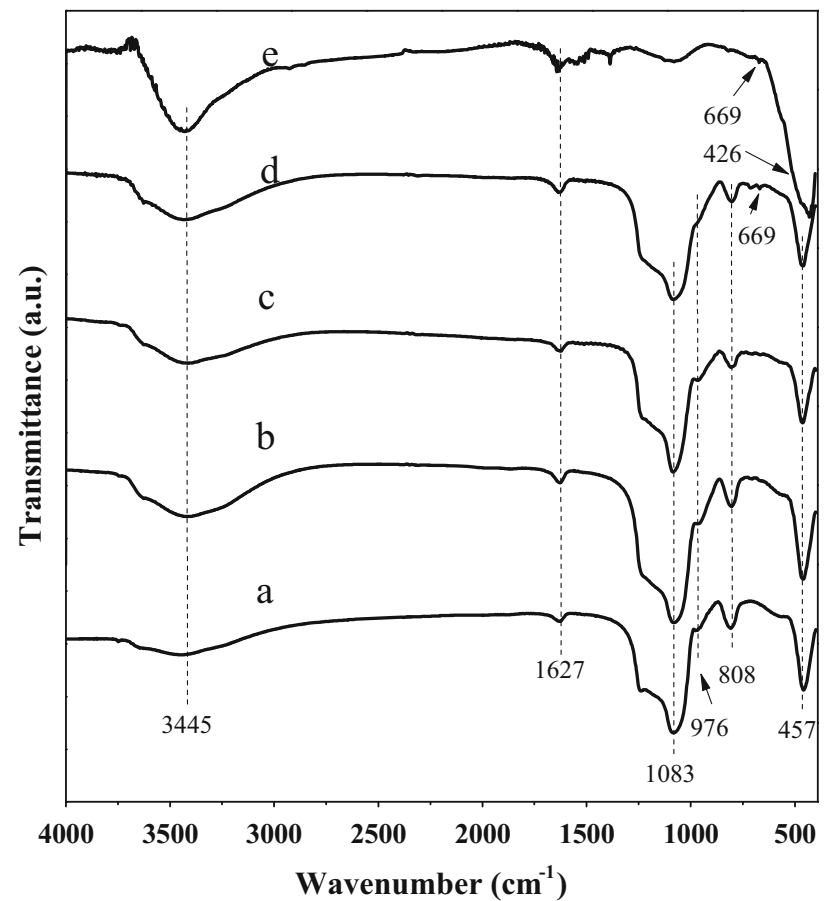

Figure 6. FT-IR spectra of samples with different nickel oxide loadings and NiO: (a) MCM-41, (b) 2Ni-MCM-41, (c) 4Ni-MCM-41, (d) 6Ni-MCM-41 and (e) NiO.

$\mathrm{Si}-\mathrm{O}-\mathrm{Si}$ in the framework of silica, ${ }^{33}$ respectively. Additionally, the absorption bands at $976 \mathrm{~cm}^{-1}$ confirmed the presence of silanol group $\mathrm{Si}-\mathrm{OH}$ and its symmetric stretching vibration; ${ }^{34}$ moreover, the intensity of the absorption peaks showed a decreasing trend with increasing loading of nickel in these samples, suggesting the decreasing of surface $\mathrm{Si}-\mathrm{OH}$ in the samples. That could be attributed to the fact that the nickel oxide nanoparticle incorporated in the silicate walls and interacted with the walls. ${ }^{35}$ And the FT-IR bands at $457 \mathrm{~cm}^{-1}$

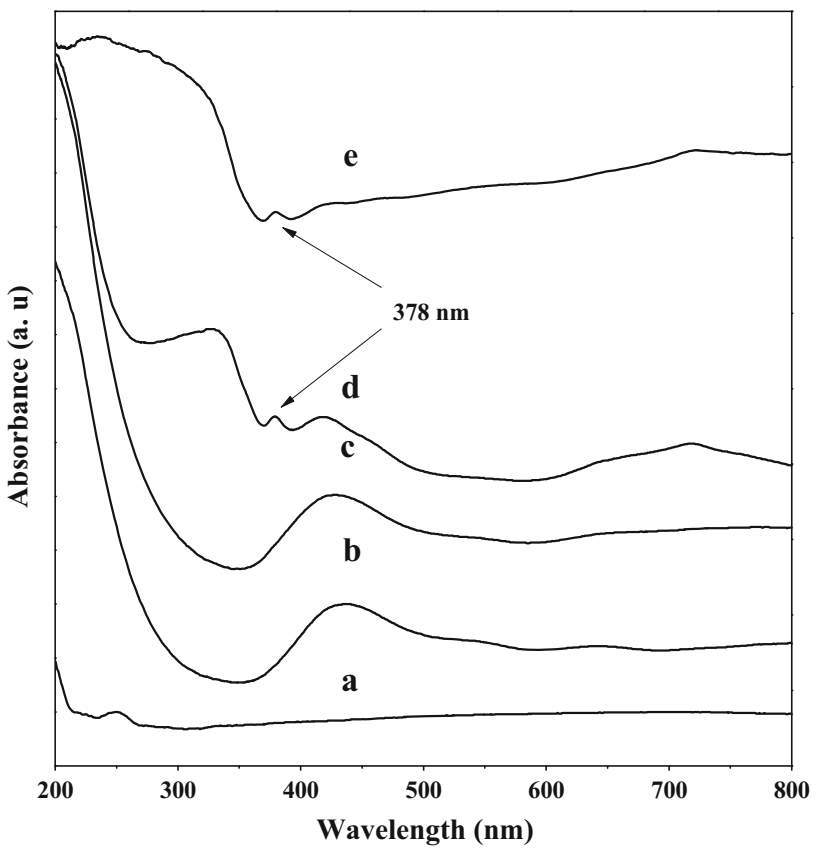

Figure 7. UV-Visible spectra of the samples with different nickel oxide loadings: (a) MCM-41, (b) 2Ni-MCM-41, (c) 4Ni-MCM-41 and (d) 6Ni-MCM-41 and (e) NiO.

are related to the bending vibration of the rocking mode of $\mathrm{Si}-\mathrm{O}-\mathrm{Si}{ }^{36}$

The presence of $\mathrm{Ni}=\mathrm{O}$ stretching vibration was confirmed by the absorption band at $669 \mathrm{~cm}^{-1}$, demonstrating the presence of $\mathrm{NiO}$ in MCM-41. ${ }^{37}$ For comparison, the FT-IR of $\mathrm{NiO}$ is also depicted in Figure 6, and the band at $669 \mathrm{~cm}^{-1}$ was also observed in $\mathrm{NiO}$, further confirming that $\mathrm{NiO}$ has been loaded into MCM-41. In addition, the absorption band at $426 \mathrm{~cm}^{-1}$ in $\mathrm{NiO}$ is assigned to the Ni-O vibration mode ${ }^{38}$ which could be 

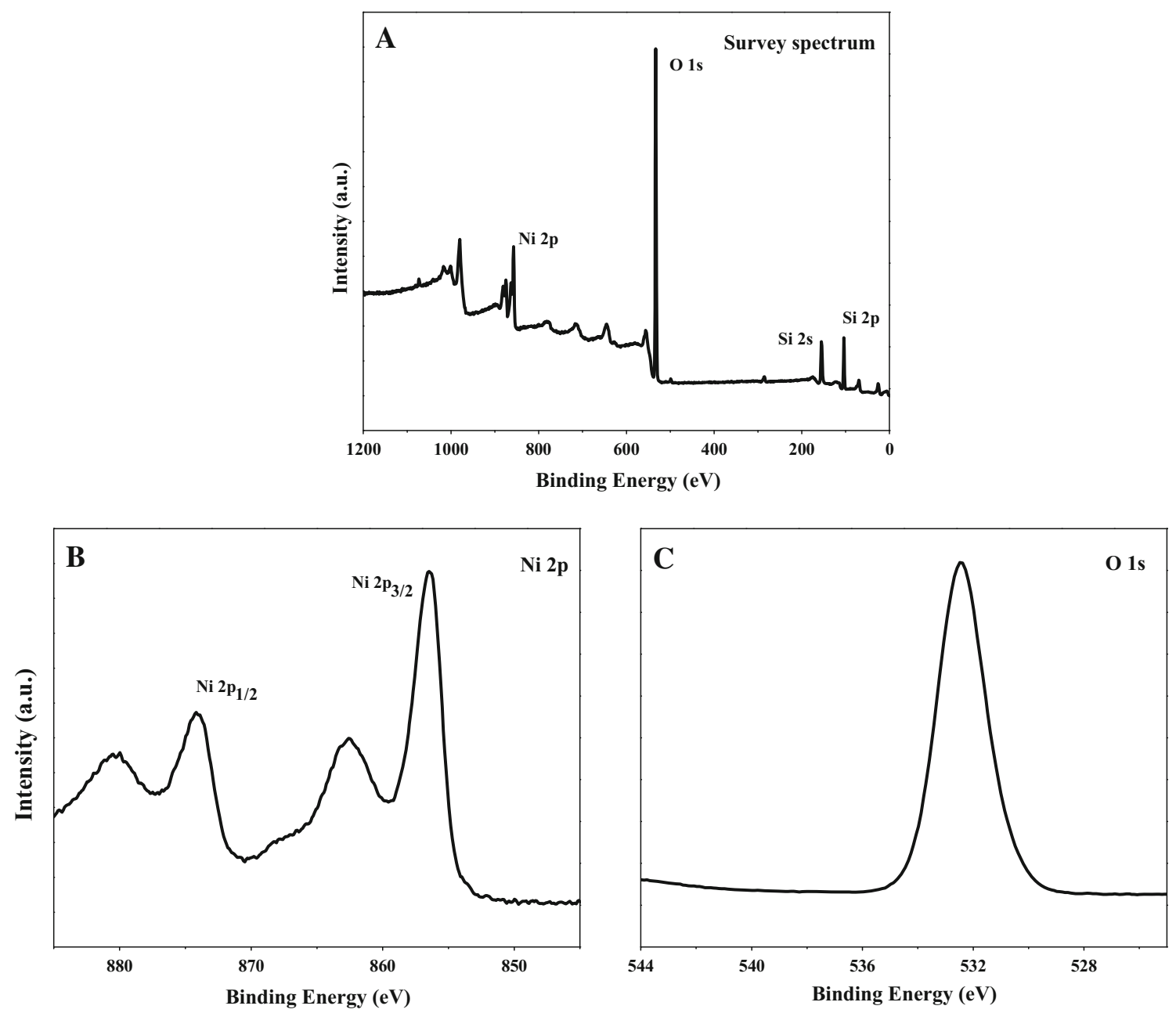

Figure 8. XPS spectra of 6Ni-MCM-41.

covered by the band at $457 \mathrm{~cm}^{-1}$ related to the bending vibration of the rocking mode of $\mathrm{Si}-\mathrm{O}-\mathrm{Si}$ in $\mathrm{Ni}$-base MCM-41.

UV-Vis spectra of the samples are shown in Figure 7. A strong absorption in the UV region was observed at $378 \mathrm{~nm}$ in 6Ni-MCM-41, which approached the absorption at $360 \mathrm{~nm}$ and $364 \mathrm{~nm}$, attributed to the band gap absorption in $\mathrm{NiO}$ that is reported in literature. ${ }^{38}$ What is more, the as-synthesized $\mathrm{NiO}$ also showed the absorption at the same wavelength, confirming the presence of $\mathrm{NiO}$ in MCM-41. While the band was not found in other Ni-based materials, which could be due to the fact that the loading of $\mathrm{NiO}$ was too little to be detected. Deservedly, the parent MCM-41 showed no absorption assigned to $\mathrm{NiO}$, either.

Figure 8 shows the XPS spectra of $6 \mathrm{Ni}-\mathrm{MCM}-41$, and the survey spectrum (Figure 8A) identified the presence of Ni, O and Si clearly. The high resolution Ni 2p XPS spectrum (Figure $8 \mathrm{~B}$ ) showed two prominent peaks at 874 and $856 \mathrm{eV}$, assigned to $\mathrm{Ni} 2 \mathrm{p}_{1 / 2}$ and $\mathrm{Ni} 2 \mathrm{p}_{3 / 2}$ states of $\mathrm{Ni}^{2+}$ in $\mathrm{NiO},{ }^{39}$ respectively. And the peak at $880 \mathrm{eV}$ corresponded to the satellite peak of $\mathrm{Ni} 2 \mathrm{p}_{1 / 2}$, while the peak at $862 \mathrm{eV}$ is assigned to the satellite peak of $\mathrm{Ni}$ $2 \mathrm{p}_{3 / 2} \cdot{ }^{40}$ Besides, as shown in Figure $8 \mathrm{C}$, the peak centered at $532 \mathrm{eV}$ could be attributed to the binding energy of $\mathrm{O} 1 \mathrm{~s}$, which is ascribed the $\mathrm{O}^{2-}$ in the $\mathrm{NiO} .{ }^{41}$ All these results confirmed the presence of $\mathrm{NiO}$.

$\mathrm{H}_{2}$-TPR technique was adopted to study the reduction behavior of supported $\mathrm{NiO}$ materials. The $\mathrm{H}_{2}$-TPR curve of 6Ni-MCM-41 is shown in Figure 9. 6Ni-MCM41 materials exhibited two reduction peaks at about $360{ }^{\circ} \mathrm{C}$ and $600{ }^{\circ} \mathrm{C}$. The peak at $360^{\circ} \mathrm{C}$ could be assigned to the reduction of the $\mathrm{NiO}$ on the external surface of MCM-41materials, and the other peak at $600{ }^{\circ} \mathrm{C}$ could be ascribed to the reduction of the $\mathrm{NiO}$ in the mesoporous walls of MCM-41materials. According to some literature, the reduction peak at $600^{\circ} \mathrm{C}$ could be related to nickel oxide layer that interacted strongly with silicate surface. ${ }^{42}$ Additionally, the peak at $600^{\circ} \mathrm{C}$ was much higher than that of $360^{\circ} \mathrm{C}$, indicating that the content of $\mathrm{NiO}$ on the external surface of MCM-41 was much less than the $\mathrm{NiO}$ in the mesoporous walls 
of MCM-41 material. That is because of the fact that $\mathrm{Ni}^{2+}$ prefers to enter the pores formed by silicone gel under the effect of capillarity during the hydrothermal reaction and incorporated into the pore wall which then formed $\mathrm{NiO}$ during the calcination process. That could also explain above analysis results. As for 2Ni-MCM41 and $4 \mathrm{Ni}-\mathrm{MCM}-41$, the content of $\mathrm{Ni}^{+}$was so little that all $\mathrm{Ni}^{2+}$ were incorporated into pore wall and highly dispersed $\mathrm{NiO}$ nanoparticles were formed eventually, so there was no $\mathrm{NiO}$ nanoparticle on the external surface of MCM-41 material, and hence NiO could not be detected. While for $6 \mathrm{Ni}-\mathrm{MCM}-41$, there was enough $\mathrm{NiO}$ present on the external surface of MCM-41 to be detected.

\subsection{Catalytic results}

The catalytic properties of all samples were evaluated by the liquid-phase epoxidation of styrene using tertbutyl hydroperoxide as oxidant and the corresponding catalytic results are presented in Table 2. For comparison, the catalytic properties of pure MCM-41 and $\mathrm{NiO}$ NPs were also investigated. As we can see, pure MCM-41 showed no catalytic activity towards the epoxidation of styrene, while $\mathrm{NiO}$ nanoparticles exhibited good catalytic activity, suggesting that nickel oxide should be the active centers for oxidation of styrene. But, as for 2Ni-MCM-41 and 4Ni-MCM-41, the conversion of styrene was poor as compared to NiO NPs although the selectivity of styrene oxide increased to a certain extent. That may be due to the fact that the loading of $\mathrm{NiO}$ was too little to achieve excellent catalytic effect, and the catalytic performance of $6 \mathrm{Ni}-\mathrm{MCM}-41$ mentioned below confirmed that. Owing to high dispersion of nickel oxide on the support and the synergistic effect between $\mathrm{NiO}$ nanoparticles and the supports, 6Ni-MCM-41 gave higher conversion and selectivity compared to pure $\mathrm{NiO}$ nanoparticles. What is more, a conclusion that $\mathrm{NiO}$ nanoparticles with smaller size possessed better catalytic performance, which can be understood by considering the size of $\mathrm{NiO}$ nanoparticles supported on MCM-41 was much smaller than that of pure $\mathrm{NiO}$ nanoparticles. The catalytic performance of $6 \mathrm{Ni}-\mathrm{MCM}-41$ was also better than that of other supported nickel oxide catalysts (Table 2).

For heterogeneous catalysts, catalyst reusability is an important parameter. So, the reusability of 6Ni-MCM41 catalyst was investigated considering it exhibited the best catalytic performance among all the catalysts. The results are shown in Figure 10A. For comparison, the reusability of pure $\mathrm{NiO}$ nanoparticles was also investigated and the results are shown in Figure 10B. As displayed in Figure 10A, a sustainable catalytic activity

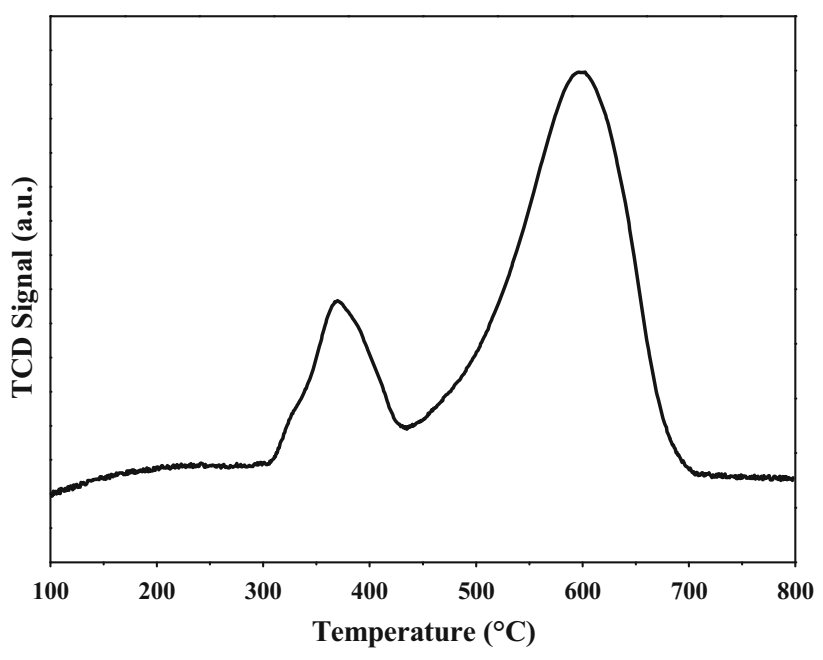

Figure 9. $\mathrm{H}_{2}-\mathrm{TPR}$ pattern of $6 \mathrm{Ni}-\mathrm{MCM}-41$.

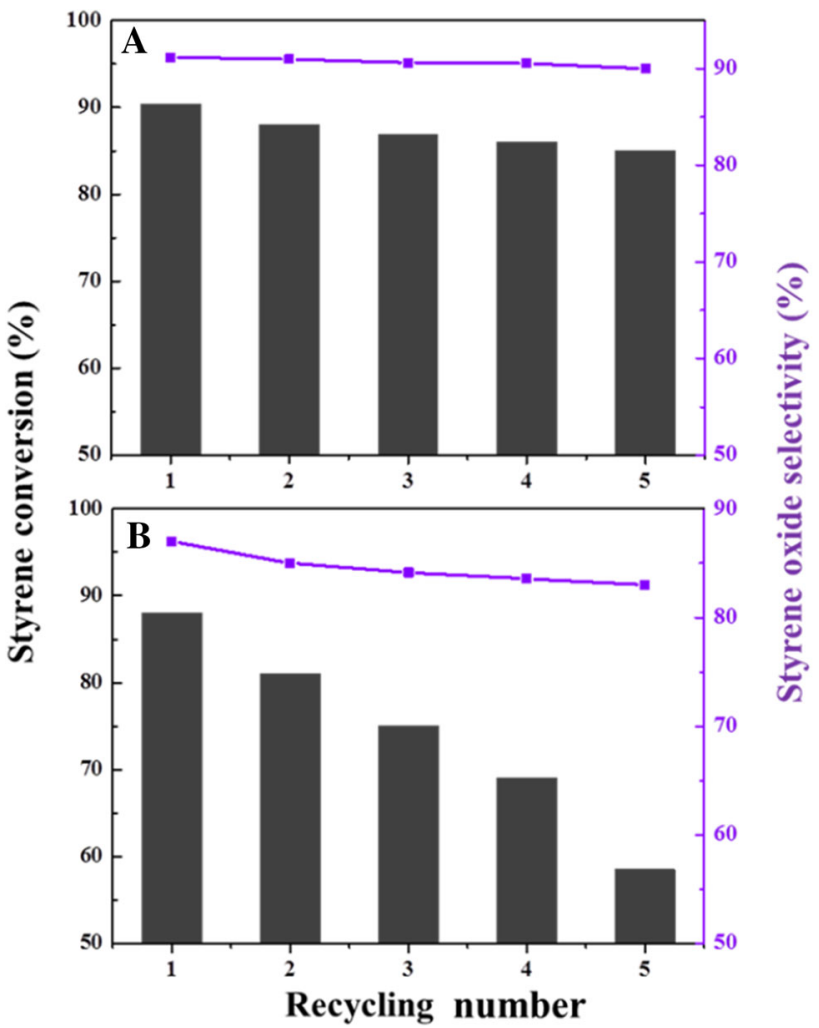

Figure 10. Reusability of 6Ni-MCM-41 (A) and pure NiO nanoparticles (B) catalysts in the epoxidation of styrene with TBHP.

was obtained even after five recycling experiments, indicating that $6 \mathrm{Ni}-\mathrm{MCM}-41$ had good stability attributed to the special interaction between nickel oxide and support. While pure $\mathrm{NiO}$ nanoparticles showed obvious reduction of the conversion efficiency, the selectivity of styrene oxide stayed at a high level. That could be due to the agglomeration of $\mathrm{NiO}$ nanoparticles without the support and dispersion in MCM-41 material. 
Table 2. The catalytic performance of all the samples in the epoxidation of styrene ${ }^{a}$

\begin{tabular}{|c|c|c|c|c|}
\hline Samples & Conversion $(\%)$ & $\mathrm{S}_{s o}^{\mathrm{b}}(\%)$ & $\mathrm{S}_{b z a}^{\mathrm{c}}(\%)$ & Ref. \\
\hline Pure MCM-41 & 0 & & & This study \\
\hline $\mathrm{NiO} N P s$ & 86.91 & 86.97 & $13 \overline{.03}$ & This study \\
\hline 2Ni-MCM-41 & 58.39 & 90.03 & 9.97 & This study \\
\hline 4Ni-MCM-41 & 75.00 & 89.76 & 10.24 & This study \\
\hline 6Ni-MCM-41 & 90.38 & 91.17 & 8.83 & This study \\
\hline $\mathrm{NiO}-\mathrm{Al}_{2} \mathrm{O}_{3}$ & 60.2 & 52.0 & 8.2 & 1 \\
\hline $\mathrm{NiO}-\mathrm{SiO}_{2}$ & 49.8 & 61.9 & 1.0 & 6 \\
\hline $\mathrm{NiO}-\mathrm{In}_{2} \mathrm{O}_{3}$ & 33.0 & 29.0 & 0.5 & \\
\hline
\end{tabular}

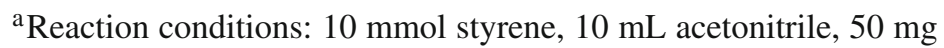
catalyst, $10 \mathrm{mmol}$ tert-butyl hydroperoxide, $80^{\circ} \mathrm{C}, 10 \mathrm{~h}$, reflux.

$\mathrm{b}_{\text {so }}=$ styrene oxide.

${ }^{\mathrm{c}} \mathrm{bza}=$ benzaldehyde.

\section{Conclusions}

In this paper, well-ordered MCM-41 containing highlydispersed $\mathrm{NiO}$ nanoparticles in mesoporous walls and on the surface was synthesized successfully. A novel templating self-assembly route that could illustrate the formation mechanism of hexagonal channel in MCM41 adequately is proposed. The characterization results revealed that $\mathrm{Ni}^{2+}$ prefers to enter the pores that are formed by silicone gel under the effect of capillarity during the hydrothermal reaction and smaller size $\mathrm{NiO}$ nanoparticles are easier to be formed on the MCM41 materials. Additionally, catalytic results indicated that $\mathrm{NiO}$ is the catalytic active center for the oxidation of styrene and the efficient catalytic property of $6 \mathrm{Ni}$ MCM-41 is attributed to high dispersion of nickel oxide on the support.

\section{Acknowledgements}

This work was supported by the National Natural Science Foundation of China (No. 21576049) and the Fundamental Research Funds for the Central Universities (No. 2242016K40082).

\section{References}

1. (a) Yadav S K and Jeevanandam P 2014 Synthesis of NiO-Al_2O_3 nanocomposites by sol-gel process and their use as catalyst for the oxidation of styrene J. Alloy. Compd. 610 567; (b) Ebadi A, Mozaffari M and Shojaei S 2014 Aerobic oxidation of cyclohexene catalyzed by NiO/MCM-41 nanocomposites in the gas phase J. Chem. Sci. 126989

2. (a) Hassan H M A, Betiha M A, Elshaarawy R F M and El-Shall M Samy 2017 Promotion effect of palladium on $\mathrm{Co}_{3} \mathrm{O}_{4}$ incorporated within mesoporous MCM-41 silica for CO Oxidation Appl. Surf. Sci. 402 99; (b) Li Z, Wu S, Yang C, Ma Y, Fu X, Peng L, Guan J and Kan Q 2017
Nano- $\mathrm{Co}_{3} \mathrm{O}_{4}$ supported on magnetic $\mathrm{N}$-doped graphene as highly efficient catalyst for epoxidation of alkenes Mol. Catal. 432267

3. Ghosh B K, Moitra D, Chandel M, Patra M K, Vadera S R and Ghosh N N 2017 CuO Nanoparticle Immobilised Mesoporous $\mathrm{TiO}_{2}$-Cobalt Ferrite Nanocatalyst: A Versatile, Magnetically Separable and Reusable Catalyst Catal. Lett. 1471061

4. (a) Qi B, Lou L, Yang Y, Wang Y, Bian W and Liu S 2014 Catalytic epoxidation of alkenes over supported manganese oxide with hydrogen peroxide: effect of supports and manganese loading Res. Chem. Intermediat. 40 2973; (b) Skliri E, Papadogiorgakis S, Lykakis I N and Armatas G S 2017 Mesoporous Assembled $\mathrm{Mn}_{3} \mathrm{O}_{4}$ Nanoparticle Networks as Efficient Catalysts for Selective Oxidation of Alkenes and Aryl Alkanes Chem. Plus. Chem. 82136

5. Ahmad A L, Koohestani B, Bhatia S and Ooi B S 2013 Mixed matrix vanadium oxide catalytic nanocomposite membrane for styrene oxidation J. Sol-Gel Sci. Technol. 67221

6. Choudhary V, Jha R and Jana P 2008 Selective epoxidation of styrene to styrene oxide by TBHP using simple transition metal oxides $\left(\mathrm{NiO}, \mathrm{CoO}\right.$ or $\left.\mathrm{MoO}_{3}\right)$ as highly active environmentally-friendly catalyst Catal. Commun. 10205

7. Tang Y, Gao H, Yang M, Wang G and Li J 2016 NiO Promoted $\mathrm{CuO}-\mathrm{NiO} / \mathrm{SBA}-15$ Composites as Highly Active Catalysts for Epoxidation of Olefins New J. Chem. 40 8543

8. Valand J, Parekh H and Friedrich H B 2013 Mixed CuNi-Co nano-metal oxides: A new class of catalysts for styrene oxidation Catal. Commun. 40149

9. Renaud A, Chavillon B, Cario L, Pleux L L and Szuwarski N 2013 Origin of the Black Color of NiO Used as Photocathode in p-Type Dye-Sensitized Solar Cells J. Phys. Chem. C $\mathbf{1 1 7} 22478$

10. (a) Zhang Y, Park M, Kim H Y and Park S 2017 Moderated surface defects of Ni particles encapsulated with $\mathrm{NiO}$ nanofibers as supercapacitor with high capacitance and energy density J. Colloid Interf. Sci. 500 155; (b) Wang S, Li W, Xin L, Wu M, Sun W and Lou X 2017 Pollen-inspired synthesis of porous and hollow NiO 
elliptical microstructures assembled from nanosheets for high-performance electrochemical energy storage Chem. Eng. J. 321546

11. (a) Wang D, Yu H, Zhu Y and Song C $2017 \mathrm{NiO}$ nanosheets rooting into $\mathrm{Ni}$-doped $\mathrm{CeO}_{2}$ microspheres for high performance of $\mathrm{CO}$ catalytic oxidation Mater. Lett. 198 168; (b) Gu Z, Bin D, Feng Y, Zhang K, Wang J, Yan B, Li S, Xiong Z, Wang C, Shiraishi Y and Du Y 2017 Seed-mediated synthesis of cross-linked Pt-NiO nanochains for methanol oxidation Appl. Surf. Sci. 411 379; (c) Hosseini S R, Ghasemi S and Kamali-Rousta M 2017 Preparation of $\mathrm{CuO} / \mathrm{NiO}$ composite nanofibers by electrospinning and their application for electro-catalytic oxidation of hydrazine J. Power Sources 343467

12. (a) Li T, Yang C, Rao X, Xiao F, Wang J and Su X 2015 Synthesis of magnetically recyclable Fe_3O_4@NiO nanostructures for styrene epoxidation and adsorption application Ceram. Int. 41 2214; (b) Abbasi A, Soleimani M, Najafi M and Geranmayeh S 2017 Synthesis of nanostructured $\mathrm{NiO} / \mathrm{Co}_{3} \mathrm{O}_{4}$ through thermal decomposition of a bimetallic (Ni/Co) metal-organic framework as catalyst for cyclooctene epoxidation J. Mol. Struct. 1133 458

13. Souza G D, Marcilio N R and Perez-Lopez O W 2017 Influence of the $\mathrm{Ni} / \mathrm{Al}$ ratio on $\mathrm{Ni}-\mathrm{Al}$ mixed oxides and their catalytic properties for ethanol decomposition $J$. Therm. Anal. Calorim. 128735

14. Sanchis R, Delgado D, Agouram S, Soriano M D, Vázquez M I, Rodríguez-Castellón E, Solsona B and Nieto J M L 2017 NiO diluted in high surface area $\mathrm{TiO}_{2}$ as an efficient catalyst for the oxidative dehydrogenation of ethane Appl. Catal. A-Gen. 53618

15. Yang F, Zhou S, Gao S, Liu X, Long S and Kong Y 2017 In situ embedding of ultra-fine nickel oxide nanoparticles in HMS with enhanced catalytic activities of styrene epoxidation Micropor. Mesopor. Mater. 23869

16. (a) Qian W, Wang H, Chen J and Kong Y 2015 Spherical V-Fe-MCM-48: The Synthesis, Characterization and Hydrothermal Stability Materials 8 1752; (b) Wang G, Liu G, Xu M, Yang Z, Liu Z, Liu Y, Chen S and Wang L 2008 Ti-MCM-41 supported phosphotungstic acid: An effective and environmentally benign catalyst for epoxidation of styrene Appl. Surf. Sci. 2552632

17. (a) Wang G, Liu G, Xu M, Yang Z, Liu Z, Liu Y, Chen S and Wang L 2008 Ti-MCM-41 supported phosphotungstic acid: An effective and environmentally benign catalyst for epoxidation of styrene Appl. Surf. Sci. 255 2632; (b) Jyothi D, Deshpande P A, Venugopal B R, Chandrasekaran S and Madras G 2012 Transition metal oxide loaded MCM catalysts for photocatalytic degradation of dyes J. Chem. Sci. 124 385; (c) Alibeik A M and Moaddeli A $2016 \mathrm{Cu}-\mathrm{MCM}-41$ nanoparticles: An efficient catalyst for the synthesis of 5-substituted $1 \mathrm{H}$ tetrazoles via [3+2] cycloaddition reaction of nitriles and sodium azide J. Chem. Sci. 12893

18. (a) Yadav S K and Jeevanandam P 2014 Synthesis of $\mathrm{NiO}-\mathrm{Al}_{2} \mathrm{O}_{3}$ nanocomposites by sol-gel process and their use as catalyst for the oxidation of styrene J. Alloy. Compd. 610 567; (b) Tang Y, Gao H, Yang M, Wang G and $\mathrm{Li} \mathrm{J} 2016 \mathrm{NiO}$ Promoted CuO-NiO/SBA-15 Composites as Highly Active Catalysts for Epoxidation of Olefins New J. Chem. 40 8543; (c) Li T, Yang C, Rao X,
Xiao F, Wang J and Su X 2015 Synthesis of magnetically recyclable $\mathrm{Fe}_{3} \mathrm{O}_{4} @ \mathrm{NiO}$ nanostructures for styrene epoxidation and adsorption application Ceram. Int. 41 2214; (d) Wang G, Liu G, Xu M, Yang Z, Liu Z, Liu Y, Chen S and Wang L 2008 Ti-MCM-41 supported phosphotungstic acid: An effective and environmentally benign catalyst for epoxidation of styrene Appl. Surf. Sci. 255 2632

19. (a) Chakraborty J, Nandi M, Mayer F H, Sheldrick S W, Sorace L, Bhaumik A and Banerjee P 2007 Nickel Complexes with $\mathrm{N}_{2} \mathrm{O}$ Donor Ligands: Syntheses, Structures, Catalysis and Magnetic Studies Eur. J. Inorg. Chem. 32 5033; (b) Nandi M, Roy P, Uyama H and Bhaumik A 2011 Functionalized mesoporous silica supported copper(II) and nickel(II) catalysts for liquid phase oxidation of olefins Dalton Trans. 4012510

20. Yadav G D and Lawate Y S 2013 Hydrogenation of Styrene Oxide to 2-Phenyl Ethanol over Polyurea Microencapsulated Mono- and Bimetallic Nanocatalysts: Activity, Selectivity, and Kinetic Modeling Ind. Eng. Chem. Res. 524027

21. Yadav S K and Jeevanandam P 2014 Synthesis of NiO$\mathrm{Al}_{2} \mathrm{O}_{3}$ nanocomposites by sol-gel process and their use as catalyst for the oxidation of styrene J. Alloy. Compd. 610567

22. Hassan H M A, Saad E M, Soltan M S, Betiha M A, Butler I S and Mostafa S I 2014 A palladium(II) 4hydroxysalicylidene Schiff-base complex anchored on functionalized MCM-41: An efficient heterogeneous catalyst for the epoxidation of olefins Appl. Catal. A-Gen. 488148

23. (a) Vetrivel S, Chen C T and Kao H M 2010 The ultrafast sonochemical synthesis of mesoporous silica MCM-41 New J. Chem. 34 2109; (b) Dehghani S and Haghighi M 2017 Sono-sulfated zirconia nanocatalyst supported on MCM-41 for biodiesel production from sunflower oil: Influence of ultrasound irradiation power on catalytic properties and performance Ultrason. Sonochem. 35 142; (c) Bhunia S, Jana S, Saha D, Dutta B and Koner S 2014 Catalytic olefin epoxidation over cobalt(II)containing mesoporous silica by molecular oxygen in dimethylformamide medium Catal. Sci. Technol. 41820

24. (a) Shen S, Chen J, Koodali R T, Hu Y, Xiao Q, Zhou J, Wang X and Guo L 2014 Activation of MCM41 mesoporous silica by transition-metal incorporation for photocatalytic hydrogen production Appl. Catal. BEnviron. 150-151 138; (b) Zhao Q, Zhou X, Ji M, Ding $\mathrm{H}$ and Jiang $\mathrm{T} 2011$ Stability and textural properties of cobalt incorporated MCM-48 mesoporous molecular sieve Appl. Surf. Sci. 2572436

25. (a) Zhao Q, Zhou X, Ji M, Ding H and Jiang T 2011 Stability and textural properties of cobalt incorporated MCM-48 mesoporous molecular sieve Appl. Surf. Sci. 257 2436; (b) Pradhan A C, Paul A and Rao G R 2017 Sol-gel-cum-hydrothermal synthesis of mesoporous Co$\mathrm{Fe} @ \mathrm{Al}_{2} \mathrm{O}_{3}-\mathrm{MCM}-41$ for methylene blue remediation $J$. Chem. Sci. 129381

26. (a) Li B, Zhu Y and Jin X 2015 Synthesis of cobaltcontaining mesoporous catalysts using the ultrasonicassisted "pH-adjusting" method: Importance of cobalt species in styrene oxidation J. Solid State Chem. 221 230; (b) Qi B, Lou L, Wang Y, Yu K, Yang Y and Liu 
S 2014 Comparison of different prepared Mn-MCM-41 catalysts in the catalytic epoxidation of alkenes with $30 \%$ $\mathrm{H}_{2} \mathrm{O}_{2}$ Micropor. Mesopor. Mat. 190275

27. Zhang Y, Gao F, Wan H, Wu C, Kong Y, Wu X, Zhao B, Dong L and Chen Y 2008 Synthesis, characterization of bimetallic Ce-Fe-SBA-15 and its catalytic performance in the phenol hydroxylation Micropor. Mesopor. Mat. 113393

28. (a) Yang F, Zhou S, Gao S, Liu X, Long S and Kong Y 2017 In situ embedding of ultra-fine nickel oxide nanoparticles in HMS with enhanced catalytic activities of styrene epoxidation Micropor. Mesopor. Mat. 238 69; (b) Tong J, Li W, Bo L, Wang H, Hu Y, Zhang Z and Mahboob A 2016 Selective oxidation of styrene catalyzed by cerium-doped cobalt ferrite nanocrystals with greatly enhanced catalytic performance J. Catal. 344 474; (c) Ren S, Yang C, Sun C, Hui Y, Dong Z, Wang J and Su X 2012 Novel NiO nanodisks and hollow nanodisks derived from $\mathrm{Ni}(\mathrm{OH})_{2}$ nanostructures and their catalytic performance in epoxidation of styrene Mater. Lett. 80 23; (d) Kumar P N, Mary J S S, Chandrakala V, Jeyarani $\mathrm{W} \mathbf{J}$ and Shyla $\mathbf{J} \mathbf{M}$, Investigation of superior electrooptical properties of $\mathrm{SnO}_{2} / \mathrm{SiO}_{2}$ nanocomposite over its individual counterpart $\mathrm{SnO}_{2}$ nanoparticles Mater. Chem. Phys. 193234

29. Ahmed S, Ramli A, Yusup S and Farooq M 2017 Adsorption behavior of tetraethylenepentamine-functionalized Si-MCM-41 for $\mathrm{CO}_{2}$ adsorption Chem. Eng. Res. Des. 12233

30. (a) Wang Y, Liang M, Fang J, Fu J and Chen X 2017 Visible-light photo-Fenton oxidation of phenol with rGO- $\alpha$-FeOOH supported on Al-doped mesoporous silica (MCM-41) at neutral pH: Performance and optimization of the catalyst Chemosphere 182 468; (b) Cuello N I, Elías V R, Mendieta S N, Longhi M, Crivello M E, Oliva M I and Eimer G A 2017 Drug release profiles of modified MCM-41 with superparamagnetic behavior correlated with the employed synthesis method Mater. Sci. Eng. C 78 674; (c) Ambursa M, Sudarsanam P, Voon L H, Hamid S B A and Bhargava S K 2017 Bimetallic $\mathrm{Cu}-\mathrm{Ni}$ catalysts supported on MCM-41 and Ti-MCM-41 porous materials for hydrodeoxygenation of lignin model compound into transportation fuels Fuel Process. Technol. 16287

31. Guan Y, Wang S, Wang X, Sun C and Huang Y 2017 In situ self-assembled synthesis of Ag-AgBr/Al-MCM41 with excellent activities of adsorption-photocatalysis Appl. Catal. B-Environ 209329

32. (a) Luo S, Fan G, Luo M, Li J and Song G 2016 Synthesis of styrene carbonate from styrene oxide and $\mathrm{CO}_{2}$ over $\mathrm{ZnBr}_{2}$ supported on MCM-41-Coated magnetic $\mathrm{Fe}_{3} \mathrm{O}_{4}$ J. $\mathrm{CO}_{2}$ Util. 14 23; (b) Fan G, Wang Y, Yan J, Song G and Li J 2017 Coupling reaction of carbon dioxide with styrene oxide over $\mathrm{Cu}(\mathrm{acac})_{2}$ and $\mathrm{n}-\mathrm{Bu}_{4} \mathrm{NBr}$ supported on $\mathrm{Fe}_{3} \mathrm{O}_{4} @ \mathrm{MCM}-41$ J. CO2 Util.18370
33. Fan G Z, Cheng S Q, Zhu M F and Gao X L 2007 Palladium chloride anchored on organic functionalized MCM-41 as a catalyst for the Heck reaction Appl. Organometal. Chem. 21670

34. (a) Karthikeyan G and Pandurangan A 2009 Heteropolyacid $\left(\mathrm{H}_{3} \mathrm{PW}_{12} \mathrm{O}_{40}\right)$ supported MCM-41: An efficient solid acid catalyst for the green synthesis of xanthenedione derivatives J. Mol. Catal. A: Chem. 311 36; (b) Wang S, Zhang Z, Liu B and Li J 2013 Silica coated magnetic $\mathrm{Fe}_{3} \mathrm{O}_{4}$ nanoparticles supported phosphotungstic acid: a novel environmentally friendly catalyst for the synthesis of 5-ethoxymethylfurfural from 5-hydroxymethylfurfural and fructose Catal. Sci. Technol. 32104

35. Yang F, Gao S, Xing C, Long S, Li X, Xi T and Kong Y 2015 Direct templating assembly route for the preparation of highly-dispersed vanadia species encapsulated in mesoporous MCM-41 channel RSC Adv. 5 72099

36. Ma T, Ding J, Shao R, Xu W and Yun Z 2017 Dehydration of glycerol to acrolein over Wells-Dawson and Keggin type phosphotungstic acids supported on MCM41 catalysts Chem. Eng. J. 316797

37. Hussain M M, Rahman M M and Asiri A M 2017 Ultrasensitive and selective 4-aminophenol chemical sensor development based on nickel oxide nanoparticles decorated carbon nanotube nanocomposites for green environment J. Environ. Sci. 5327

38. Salavati-Niasari M, Davar F and Fereshteh Z 2010 Synthesis of nickel and nickel oxide nanoparticles via heattreatment of simple octanoate precursor J. Alloys Compd. 494410

39. Hanifehpour Y, Morsali A, Mirtamizdoust B, Joo S W and Soltani B 2017 Thermolysis synthesis of pure phase $\mathrm{NiO}$ from novel sonochemical synthesized Ni(II) nano metal-organic supramolecular architecture Ultrason. Sonochem. 37430

40. Fang J, Zhang Y, Zhou Y, Zhao S, Zhang C, Huang M and Gao Y 2017 Synthesis of $\mathrm{NiO}-\mathrm{TiO}_{2}$ hybrids $/ \mathrm{mSiO}_{2}$ yolk-shell architectures embedded with ultrasmall gold nanoparticles for enhanced reactivity Appl. Surf. Sci. 412 616

41. Yang C, Qing Y, An K, Zhang Z, Wang L and Liu C 2017 Facile synthesis of the N-doped graphene/nickel oxide with enhanced electrochemical performance for rechargeable lithium-ion batteries Mater. Chem. Phys. 195149

42. (a) Qin J, Li B, Zhang W, Lv W, Han C and Liu J 2015 Synthesis, characterization and catalytic performance of well-ordered mesoporous Ni-MCM-41 with high nickel content Micropor. Mesopor. Mat. 208 181; (b) Wu C, Wang L, Williams P T, Shi J and Huang J 2011 Hydrogen production from biomass gasification with Ni/MCM-41 catalysts: Influence of Ni content Appl. Catal. B-Environ. 108-109 6 